\title{
Control of Pollutant Emissions in Natural Gas Diffusion Flames by Using Cascade Burners
}

\section{ANNUAL/FINAL TECHNICAL REPORT}

09/01/2000 through 8/31/2001

Dr. Ala Qubbaj, Engineering Department

$12 / 30 / 2001$

DE-FG26-00NT40831

Faculty/Student Research Training Grant

University of Texas pan American

1201 West University Drive

Edinburg, Texas 78539-2999 


\section{DISCLAIMER NOTICE}

This report was prepared as an account of work sponsored by an agency of the United States Government. Neither the united states Government nor any agency thereof, or any of their employees, makes any warranty, express or implied, or assumes any legal liability or responsibility of the accuracy, completeness, or usefulness of any information, apparatus, product, or process disclosed, or represents that its use would not infringe privately owned rights. Reference herein to any specific commercial product, process, or service by trade name, trademark, manufacturer, or otherwise does not necessarily constitute or imply its endorsement, recommendation, or favoring by the United States Government or ant agency thereof. The views and opinions of authors expressed herein do not necessarily states or reflect those of the United States Government or any agency thereof. 


\begin{abstract}
The goal of this exploratory research project is to control the pollutant emissions of diffusion flames by modifying the air infusion rate into the flame. The modification was achieved by installing a cascade of venturis around the burning gas jet. The basic idea behind this technique is controlling the stoichiometry of the flame through changing the flow dynamics and rates of mixing in the combustion zone with a set of venturis surrounding the flame. A natural gas jet diffusion flame at burner-exit Reynolds number of 5100 was examined with a set of venturis of specific sizes and spacing arrangement.

The thermal and composition fields of the baseline and venturi-cascaded flames were numerically simulated using $\mathrm{CFD}-\mathrm{ACE}+$, an advanced computational environment software package. The instantaneous chemistry model was used as the reaction model. The concentration of NO was determined through CFD-POST, a post processing utility program for CFD-ACE+. The numerical results showed that, in the near-burner, midflame and far-burner regions, the venturi-cascaded flame had lower temperature by an average of $13 \%, 19 \%$ and $17 \%$, respectively, and lower $\mathrm{CO}_{2}$ concentration by $35 \%, 37 \%$ and $32 \%$, respectively, than the baseline flame. An opposite trend was noticed for $\mathrm{O}_{2}$ concentration; the cascaded flame has higher $\mathrm{O}_{2}$ concentration by $7 \%, 26 \%$ and $44 \%$, in average values, in the near-burner, mid-flame and far-burner regions, respectively, than in the baseline case. The results also showed that, in the near-burner, mid-flame, and farburner regions, the venturi-cascaded flame has lower NO concentrations by $89 \%, 70 \%$ and $70 \%$, in average values, respectively, compared to the baseline case.

The numerical results substantiate that venturi-cascading is a feasible method for controlling the pollutant emissions of a burning gas jet. In addition, the numerical results were useful to understand the thermo-chemical processes involved. The results showed that the prompt-NO mechanism plays an important role besides the conventional thermalNO mechanism. The computational results of the present study need to be validated experimentally
\end{abstract}




\section{TABLE OF CONTENTS}

Title Page

Disclaimer Notice

Abstract

Table of Contents

List of Graphical Materials

1. Introduction

2. Physical Model

3. Numerical Modeling and Computations

$\underline{3.1}$ Geometric Modeling and Grid Generation

3.2 Reaction Model

$\underline{3.3}$ Assumptions and Boundary conditions

3.4 NO Post Processing

4. Results and Discussion

4.1 Flame Temperature Profiles

4.2 Carbon Dioxide Concentration Profiles

$\underline{4.3}$ Oxygen Concentration Profiles

4.4 Nitric Oxide Concentration Profiles

4.5 Radial and Axial Velocity Profiles

5. Conclusions

6. References

List of Acronyms and Abbreviations 


\section{LIST OF GRAPHICAL MATERIALS}

Figure 1 Physical model, venturi-cascade dimensions and measurement locations

Figure 2 Radial temperature profiles for the baseline and cascaded flames at different axial location

Figure 3 Radial $\mathrm{CO} 2$ profiles for the baseline and cascaded flames at different axial locations

Figure 4 Radial O2 profiles for the baseline and cascaded flames at different axial locations

Figure 5 Radial thermal-NO profiles for the baseline and cascaded flames at different axial locations

Figure 6 Radial profiles of axial $(\mathrm{U})$ and radial $(\mathrm{V})$ velocity components for the baseline and cascaded flames at $\mathrm{x} / \mathrm{d}=80$ (mid-level of venturi 2) 


\section{INTRODUCTION}

The key for controlling the production of pollutants in flames is to control the local air-fuel ratio. In premixed flames, this may be achieved by staging of fuel-air mixing so that the residence time of the flame is mostly confined to fuel-rich or fuel-lean zones (Bowman, 1992). In partially nonpremixed flames, except in the near-burner region, the local air-fuel ratio depends upon the air-infusion rate into the burning jet, which can be controlled either by changing the flow dynamics or manipulating the downstream flow characteristics of the gas jet. The application of non-axisymmetric burner exit geometries (Gollahalli et al., 1992; Gutmark et al.,1991; Schadow et al., 1989; Kamal and Gollahalli, 1993; Papanikolau and Wierzba, 1996; Papanikolau et al., 1997) is an example of such a technique that showed some improvements in the combustion and emission characteristics of burning gas jets.

A new control technique was tested in this faculty/student exploratory research project. In this technique the downstream flow characteristics are manipulated by employing the method of venturi-cascading, in which a set of venturis is arranged around the flame so that each venturi acts as an ejector that accelerates the air inflow into the combustion zone. The present study is an investigation, through which, venturicascading and its influence on the combustion characteristics on gas jet diffusion flames are numerically modeled and analyzed. The general objective is to computationally study the feasibility of the technique. The specific objectives are to understand the thermochemical processes involved. 


\section{PHYSICAL MODEL}

The physical model consists of a steel combustion chamber of $76 \mathrm{~cm}$ x $76 \mathrm{~cm}$ crosssection and $163 \mathrm{~cm}$ height (Fig. 1). A circular opening in the base plate covered with a wire-mesh screen allowed the insertion of a vertically mounted fuel burner. This opening also allowed natural convection of air into the chamber. The top of the chamber was connected to the atmosphere through an exhaust duct. The fuel burner was a stainlesssteel circular tube of $2 \mathrm{~mm}$ i.d. The tube was longer than 150 hydraulic diameters to ensure a fully developed flow at the exit. The ambient pressure of the laboratory was maintained slightly above the atmospheric pressure to insure a positive draft inside the combustion chamber. The set of venturis consisted of four identical venturis to form a cascade, the dimensions of the venturis and their locations are given in table 1 and shown in Fig 1. The conditions used in the numerical simulation are given in Table 1.

\section{Table 1: Conditions used in the computations}

\begin{tabular}{ll}
\hline Fuel & Natural Gas $(95 \%+)$ \\
Jet diameter $(\mathrm{d})$ & $2 \mathrm{~mm}$ \\
Jet exit Reynolds number & 5100 \\
Jet exit velocity & $11 \mathrm{~m} / \mathrm{s}$ \\
Convected air velocity & $0.25 \mathrm{~m} / \mathrm{s}$ \\
Venturi throat diameter (D) & $70 \mathrm{~mm}$ \\
Venturi height $(\mathrm{H})$ & $70 \mathrm{~mm}$ \\
Venturi inlet diameter (DI) & $140 \mathrm{~mm}$ \\
Venturis location ${ }^{*}$ & $\mathrm{x} / \mathrm{d}=0,80,160,240$ \\
Axial locations & near-burner $(\mathrm{x} / \mathrm{d}=20)$ \\
& mid-flame $(\mathrm{x} / \mathrm{d}=100)$ \\
& far-burner $(\mathrm{x} / \mathrm{d}=180)$ \\
Ambient temperature & $295 \mathrm{~K}$ \\
Ambient pressure & $100 \mathrm{kPa}$ \\
* See Fig. 1 &
\end{tabular}



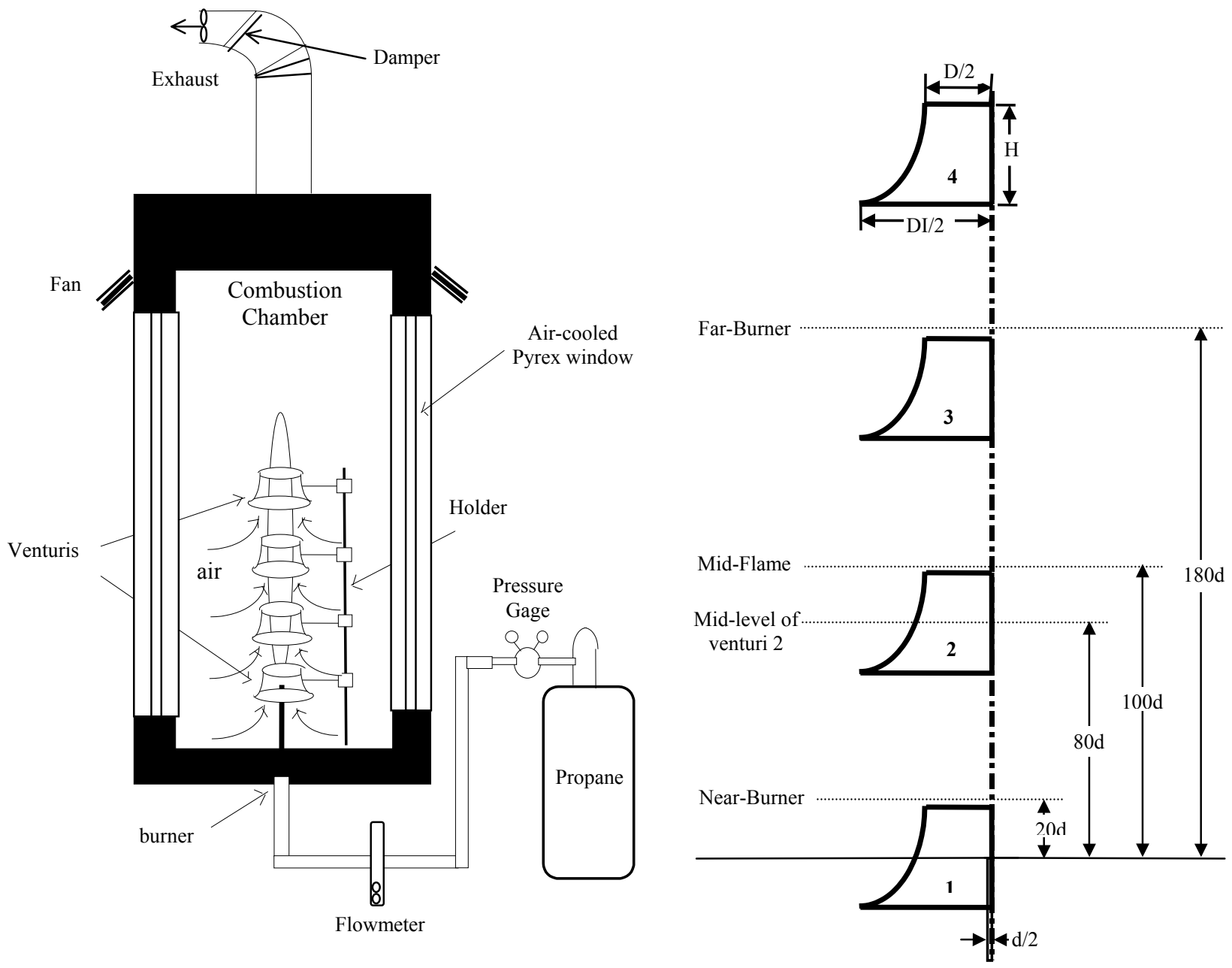

Fig.1 Physical Model (left) Venturi-cascade dimensions and measurement locations (right) 


\section{NUMERICAL COMPUTATIONS}

\subsection{Computational Model}

The numerical computations were conducted using the CFDRC-ACE+ (advanced computational environment) software package*, version 5.0, 1998, in which CFD-GEOM (Interactive Geometric Modeling and Grid Generation software) and CFD-VIEW (3-D Computer Graphics and Animation Software) are incorporated. CFD-POST, a post processing utility program for CFD-ACE + was also employed in computing NO emissions.

The computational domain encompassed half of the flame jet (assuming axisymmetric flow conditions), extended to $64 \mathrm{~cm}$ in the axial direction and $14 \mathrm{~cm}$ in the radial direction. A total number of 11160 cells $(248 \times 45)$ were generated with increasing spacing in the radial and axial directions; this provided an adequate resolution where gradients were large, near the centerline, and saved CPU time where gradients were small, near the edges. All important factors such as a right-handed grid, smooth transition from small to large cells, and grid orthogonality were taken into account in the grid generation process, and they did have a beneficial effect on the convergence of the solution. Moreover, the computational results were checked for grid independence; it showed that increasing the total number of cells to $15840(288 \times 55)$, i.e., reducing the grid size by one third of its current configuration, produced only a change of $2-3 \%$ in temperature.

The venturis were modeled as two-dimensional axisymmetric convergent nozzles around the jet. Four identical nozzles of the dimensions and spacing provided in Table (1) were used to form the cascade (Fig. 1). With the cascade being added to the jet, the geometric complexity of the problem increased; which required multi-domain structured grid systems to be connected and matched on the boundaries. The CFD-GEOM module (Interactive Geometric Modeling and Grid Generation Software) in the CFD-ACE+ package was used for geometric modeling and grid generation purposes.

A cell-centered control volume approach was used, in which the discretized equations or the finite difference equations (FDE) were formulated by evaluating and integrating fluxes across the faces of control volumes in order to satisfy the continuety, momentum

\footnotetext{
* From CFD Research Corporation, Huntsville, Alabama.
} 
energy and mixture fractins conservation equations. The first order upwind scheme was used for evaluating convective fluxes over a control volume. The well-known SIMPLEC algorithm, proposed by Van Dooormal and Raithby (1984), was used for velocity pressure-coupling.

\subsection{Reaction Model}

The reaction model used by $\mathrm{CFD}-\mathrm{ACE}+$ was the instantaneous chemistry model in which the reactants are assumed to react completely upon contact. The reaction rate is infinitely rapid and one reaction step is assumed. Two reactants, which are commonly referred to as "fuel" and "oxidizer", are involved. A surface "flame sheet" separates the two reactants. The mass fractions for this model are computed by first using Eq. 1 to obtain the composition that would occur without the reaction. The "unreacted" composition, denoted by the superscript " $u$ ", is given by

$$
\left(\mathrm{Y}_{\mathrm{i}}\right)^{\mathrm{u}}=\sum_{\mathrm{k}=1}^{\mathrm{K}} \xi_{\mathrm{ik}} \mathrm{f}_{\mathrm{k}}
$$

where $\xi_{\mathrm{ik}}$ is the mass fraction of the $\mathrm{i}^{\text {th }}$ species in the $\mathrm{k}^{\text {th }}$ mixture, $\mathrm{Y}_{\mathrm{i}}$ is the mass fraction of the $i^{\text {th }}$ species and $f_{k}$ is the mixture fraction of the $k^{\text {th }}$ mixture. The change in composition due to the instantaneous reaction is then added to the unreacted mass fractions, as described below.

A stoichiometrically correct reaction step needs to be specified. The mass of species $i$ produced per unit mass of fuel consumed is

$$
r_{i}=-\frac{v_{i} M_{i}}{v_{f} M_{f}}
$$

where $v$ is the stoichiometric coefficient of the species in the overall reaction; positive for product species and negative for fuel and oxidizer. The instantaneous reaction mechanism consumes either all the fuel or all the oxidizer, whichever is limiting. The amount of fuel consumed is

$$
\Delta Y_{f}=\min \left(\frac{\left(Y_{f}\right)^{u}}{-r_{f}}, \frac{\left(Y_{o x}\right)^{u}}{-r_{o x}}\right)
$$

The change in each species due to the reaction is proportional to the change in fuel, with the proportionality constant given by Eq. 2. The mass fraction of each species is then given by 


$$
\mathrm{Y}_{\mathrm{i}}=\left(\mathrm{Y}_{\mathrm{i}}\right)^{\mathrm{u}}+\mathrm{r}_{\mathrm{i}} \Delta \mathrm{Y}_{\mathrm{f}}
$$

The right-hand side of the above equation is only a function of the $\mathrm{K}$ mixture fractions. Therefore, K-1 transport equations were solved for the mixture fractions. These equations have no source terms due to chemical reactions.

\section{$\underline{3.3 \text { Assumptions and Boundary Conditions }}$}

The following approximations and assumptions have been made to simplify the numerical analysis: Laminar, steady, axisymmetric 2-dimenssional flow, Newtonian fluid and ideal gas behavior, uniform inlet velocity profiles, one-step, surface-sheet and instantaneous reaction, soot-free diffusion flame, and negligible radiation losses from the flame.

The boundary conditions are provided from the physics of the problem. Due to the symmetry around the x-axis, only one half of the flame is modeled. Both the centerline and the boundary at radius $y=14 \mathrm{~cm}$ are specified as symmetry lines in both the baseline and cascaded cases. The fuel inlet velocity is $11 \mathrm{~m} / \mathrm{s}$; based on the jet-exit diameter and Reynolds number (Table 1). The coflow air velocity convected into the chamber through the fine-mesh screens is $0.25 \mathrm{~m} / \mathrm{s}$. The venturis were simulated as thin-wall solid boundaries; by default this provides the no-slip condition $(\mathrm{U}=0, \mathrm{~V}=0)$ on both sides. A similar thin-wall boundary condition is also assigned for the tube-burner wall. The exit boundary is assigned a constant pressure (atmospheric) value.

\section{$\underline{3.4 \text { NO Post Processing }}$}

The concentration of NO was predicted by post processing the results from CFD$\mathrm{ACE}^{+}$using the thermal-NO (Zeldovich) mechanism through CFD-POST (a post processing utility program for CFD-ACE+ package). The NO concentration field was solved by calculating the NO source term for each cell and using the convective and diffusive fields as determined by CFD-ACE+. The solution assumes that the upwind scheme was used in CFD-ACE+. It also assumes that NO post processing has a negligible effect on the heat release and the overall flow field.

The concentration of NO was predicted using the thermal-NO (Zeldovich) mechanism, which consists of the following three reactions: 


$$
\begin{aligned}
& \mathrm{N}_{2}+\mathrm{O} \leftrightarrow \mathrm{NO}+\mathrm{O} \\
& \mathrm{N}+\mathrm{O}_{2} \leftrightarrow \mathrm{NO}+\mathrm{O} \\
& \mathrm{N}+\mathrm{OH} \leftrightarrow \mathrm{NO}+\mathrm{H}
\end{aligned}
$$

These reactions were solved using the extended Zeldovich method of CFD-POST (CFDRC, 1998). The production of NO by the extended method can be expressed as:

$$
\frac{\mathrm{d}[\mathrm{NO}]}{\mathrm{dt}}=2 \mathrm{k}_{1}\left[\mathrm{~N}_{2}\right][\mathrm{O}]\left\{\frac{1-[\mathrm{NO}]^{2} / \mathrm{K}\left[\mathrm{N}_{2}\right]\left[\mathrm{O}_{2}\right]}{1+\mathrm{k}_{-1}[\mathrm{NO}] /\left(\mathrm{k}_{2}\left[\mathrm{O}_{2}\right]+\mathrm{k}_{3}[\mathrm{OH}]\right)}\right\}
$$

where

$$
\mathrm{K}=\left(\frac{\mathrm{k}_{1}}{\mathrm{k}_{-1}}\right)\left(\frac{\mathrm{k}_{2}}{\mathrm{k}_{-2}}\right)
$$

and $\mathrm{k}_{1}, \mathrm{k}_{2}, \mathrm{k}_{3}, \mathrm{k}_{-1}, \mathrm{k}_{-2}$ and $\mathrm{k}_{-3}$ are forward and reverse reaction rate constants for the three reactions above. Since the concentration of NO appears in the right hand side of the above equation for NO production, the NO source term is determined by an iterative process. All the species concentrations appearing in the above equation $\left(\mathrm{O}_{2}, \mathrm{~N}_{2}, \mathrm{O}\right.$ and $\mathrm{OH})$ must be available from the reaction model used in CFD-ACE+. The reactions rates are those of Miller and Bowman (1989) and are shown in Table 2.

Table 2: Extended Zeldovich Reaction Rate Constants

\begin{tabular}{cccc}
\multicolumn{4}{c}{$\left(k=A T^{\beta} e^{-E / R T}\right)$} \\
\hline Constant & $\mathbf{A}$ & $\beta$ & E/R \\
\hline $\mathrm{k}_{-1}$ & $3.7 \mathrm{E} 9$ & 0.3 & 0.0 \\
$\mathrm{k}_{-2}$ & $6.40 \mathrm{E} 6$ & 1.0 & 3160 \\
$\mathrm{k}_{-3}$ & $3.80 \mathrm{E} 10$ & 0.0 & 0.0 \\
\hline
\end{tabular}




\section{RESULTS AND DISCUSSION}

\section{$\underline{4.1 \text { Flame Temperature Profiles }}$}

Figures $2(a, b, c)$ show the theoretically predicted radial temperature profiles, for the baseline and cascaded flames, at three axial locations; near burner $(\mathrm{x} / \mathrm{d}=20)$, mid-flame $(\mathrm{x} / \mathrm{d}=100)$ and far-burner $(\mathrm{x} / \mathrm{d}=180)$ regions, respectively. From the theoretical profiles, the following observations can be made: (i) the off-axis peak exists in all three regions of concern, however, its radial location moves further outward in the mid-flame and farburner regions; (ii) the peak temperature of the cascaded flame drops by $9 \%, 6 \%$ and $1 \%$ in the near-burner, mid-flame and far-burner locations, respectively; from its baseline values; (iii) the overall average temperature of the cascaded flame decreases by $13 \%$, $19 \%$ and $17 \%$ in the same three regions of concern, respectively, from its baseline values; (iv) all cascaded profiles are shifted inward towards the fuel-rich side of the flame, the least shift is observed in the near-burner region; (v) the cascaded flame has significantly lower temperatures in the fuel-lean side of the flame, compared to the baseline case. However, it has higher valley temperatures in the fuel-rich side; (vi) the temperature changes, caused by the cascade on the flame show that the venturi-cascade is more influential in the fuel-lean side than in the fuel-rich side; (vii) the cascade effect is the least in the near-burner region, but increases significantly in both mid-flame and farburner regions.

The observed shift of the temperature profile towards the fuel-rich side of the flame is a direct result of the venturi effect which ejects the co-flow air stream into the core of the combustion zone, thereby leading to better mixing rates of air with the unburned fuel and the consequent shift of the stoichiometric contour towards the center of the flame. This leaning process has two different effects on the fuel-lean and fuel-rich sides of the flame; the temperature of the latter increases while that of the former decreases. The valley temperature increase in the fuel-rich side of the cascaded flame is a result of higher oxygen availability, pushing the mixture towards stoichiometry. On the other hand, the temperature decrease in the lean side is due to the excess air; pushing the mixture far away from stoichiometry. The net effect of the cascade on the flame temperature is determined by the resultant of the two aforementioned factors. 
The theoretical temperature profiles, in all three regions, show that the changes brought by cascading to the fuel-lean side are more significant than those brought to the fuel-rich side. This is reasonable, since the lean side of the flame is closer to the venturis and therefore should be the most affected. This explains the theoretical predicted decrease in overall and peak temperatures by the effect of cascading.

\subsection{Carbon Dioxide Concentration Profiles}

Figures $3(a, b, c)$ show the theoretically-predicted radial concentration profiles of $\mathrm{CO}_{2}$ in the near-burner, mid-flame and far-burner regions, respectively, at the same conditions pertaining to the earlier predicted temperature profiles. From the theoretical profiles the following can be observed: (i) the off-axis peak exists in the three regions of concern; (i) the peak $\mathrm{CO}_{2}$ concentrations for the baseline flame are at $\mathrm{r} / \mathrm{d} 2.82,5.56$ and 7.84 in the near-burner, mid-flame and far-burner regions, respectively. The corresponding $\mathrm{CO}_{2}$ peaks in the cascaded flame are at $\mathrm{r} / \mathrm{d} 2.82,4.84$ and 6.3; (iii) The previously mentioned peak $\mathrm{CO}_{2}$ radial positions coincide well with those of temperature at the same conditions; (iv) The cascaded $\mathrm{CO}_{2}$ profiles are shifted inward, like the earlier temperature profiles; the least shift occurs in the near-burner region while the most occurs in the far-burner region; (v) Even though the peak $\mathrm{CO}_{2}$ values match well with peak temperatures, the $\mathrm{CO}_{2}$ profiles appear to be sharper and narrower than those of temperature; (vi) The predicted $\mathrm{CO}_{2}$ valley concentrations are much lower than the temperature-based expectations; $\mathrm{CO}_{2}$ decreases sharply from its peak value to approach zero in the early fuel-rich region, whereas the corresponding temperature values are still fairly high; (vii) The average $\mathrm{CO}_{2}$ concentration in the cascaded flame decreases by $35 \%$, $37 \%$ and $32 \%$ from its baseline values, in the three axial locations of concern, respectively; this corresponds to $13 \%, 19 \%$ and $17 \%$ average decrease in theoreticalpredicted temperatures at same conditions; (viii) In all three regions, the cascaded flame has higher $\mathrm{CO}_{2}$ concentrations in the fuel-rich side of the flame compared to the baseline case. However, it has lower $\mathrm{CO}_{2}$ concentrations in the fuel-lean side. Same behavior has been noticed for temperature profiles.

The existence of off-axis peaks, their radial locations, the inward shift of the profiles, the $\mathrm{CO}_{2}$ increase in the fuel rich side and decrease in the fuel-lean side, the overall 
decrease of $\mathrm{CO}_{2}$ in the cascaded flame; all follow the temperature profiles and similar explanations apply. This is reasonable, since $\mathrm{CO}_{2}$ is a direct combustion product which depends primarily on temperature and stoichiometry of the flame. However, the sharpnarrow appearance with very low valley $\mathrm{CO}_{2}$ concentrations does not keep pace with the corresponding temperature trends. The most probable reason is the chemistry-reaction model that has been employed by CFD-ACE + , which assumes instantaneous, infinitely rapid and surface-sheet reaction upon contact of the reactants, thereby not allowing enough time for $\mathrm{CO}_{2}$ to diffuse towards the fuel-lean and fuel-rich sides of the flame, and therefore leading to the observed narrow and sharp $\mathrm{CO}_{2}$ profiles.

\subsection{Oxygen Concentration Profiles}

Figures $4(\mathrm{a}, \mathrm{b}, \mathrm{c})$ show the predicted $\mathrm{O}_{2}$ radial concentration profiles in the nearburner, mid-flame and far-burner regions, respectively. From the theoretical predicted profiles the following can be observed: (i) the $\mathrm{O}_{2}$ concentration starts with a zero value at the central axis and remains zero in the fuel-rich side until it reaches the stoichiometric contour $(\phi=1)$, then starts to build up in the radial outward direction until it attains its atmospheric value $\left(\sim 21 \%\right.$ ) near the outside boundary of the flame; (ii) $\mathrm{O}_{2}$ profiles spread outward in the radial direction and become wider in the mid-flame and far-burner locations; (iii) $\mathrm{O}_{2}$ in the baseline flame starts to build up at r/d 2.82, 5.66 and 7.06 in the near-burner, mid-flame and far-burner, respectively, whereas, the corresponding build up radial positions for the cascaded flame are $\mathrm{r} / \mathrm{d}$ 2.21, 4.14 and 5.56; (iv) $\mathrm{O}_{2}$ profiles in the cascaded flame build up faster and consequently attain the ambient value earlier than the baseline ones; (v) $\mathrm{O}_{2}$ concentration in the cascaded flame increases by an average of $7 \%$, $26 \%$ and $44 \%$ compared to its baseline values, in the near-burner, mid-flame and farburner axial locations, respectively; (vi) $\mathrm{O}_{2}$ profiles in the cascaded flame are shifted inward, similar to what has been observed in the earlier temperature and $\mathrm{CO}_{2}$ profiles.

The zero $\mathrm{O}_{2}$ concentration observed in the fuel-rich region is consistent with the absence of $\mathrm{CO}_{2}$ values observed earlier in the same region. $\mathrm{O}_{2}$ has been entirely consumed at the stoichiometric contour; which is what has been assumed by the flame sheet approximation made in the reaction model employed by CFD-ACE+. The outward spread of the profile in the mid-flame and far-burner regions is a result of the jet growth 
and greater quantities of air entrained into to the gas jet flame as it proceeds downstream. The faster build-up rate in the cascaded flame compared to the baseline case is a clear indication of the higher rates of mixing with air provided by the cascade of venturis. The average increase of $\mathrm{O}_{2}$ in the cascaded flame compared to the baseline case is the direct cause of the temperature drop observed and explained earlier. The inward shift of the profiles has been noticed for earlier temperature and $\mathrm{CO}_{2}$ profiles too, and therefore the same aforementioned explanation applies.

\section{$\underline{4.4 \text { Nitric Oxide Concentration Profiles }}$}

Figures $5(\mathrm{a}, \mathrm{b}, \mathrm{c})$ show the radial concentration profiles of predicted thermal-NO for the baseline and cascaded flames in the near-burner, mid-flame and far-burner axial locations, respectively. Thermal-NO concentrations were calculated using CFD-POST post processing utility program of $\mathrm{CFD}-\mathrm{ACE}+$. Appropriate reactions in the detailed kinetics model were turned on to evaluate the influence of the thermal mechanism on NO production using the extended Zeldovich mechanism.

From the theoretical thermal-NO profiles, the following observations can be made: (i) thermal-NO profiles follow the trends of temperature profiles, and peak concentrations coincide well with peak temperatures; (ii) the peak thermal-NO concentrations for the baseline flame are: $11 \mathrm{ppm}, 20 \mathrm{ppm}$ and $39 \mathrm{ppm}$ in the near-burner, mid-flame and farburner locations, respectively. However, the corresponding peaks for the cascaded flame are: 1 ppm, 7 ppm and 14 ppm; (iii) thermal-NO concentrations for the cascaded flame decrease by an average of $89 \%, 70 \%$ and $70 \%$ in the near-burner, mid-flame and farburner regions, respectively, compared to the baseline case. However, the corresponding decrease in predicted temperatures are $13 \%, 19 \%$ and $17 \%$.

Since NO concentrations have been predicted by the thermal-NO mechanism, it is quite expected to follow the temperature profiles and consequently have same peak radial locations and trends. However, the influence of the cascade on thermal-NO is much stronger than its earlier predicted influence on temperature. This can be explained by examining the equation for NO production by extended Zeldovich mechanism (Eq. 8), from which, the rate of NO production is seen to be not only a function of the forward and reverse reaction rate constants $\left(\mathrm{k}_{1}, \mathrm{k}_{2}, \mathrm{k}_{3}, \mathrm{k}_{-1}, \mathrm{k}_{-2}, \mathrm{k}_{-3}\right)$, which are in turn strong 
functions of temperature $\left(\mathrm{k}=\mathrm{AT}^{\beta} \mathrm{e}^{-\mathrm{E} / \mathrm{RT}}\right)$, but also a function of concentrations of $\mathrm{O}_{2}, \mathrm{~N}_{2}, \mathrm{O}$ and $\mathrm{OH}$. In other words, temperature has a strong influence on thermal-NO, through the exponential dependence, and the concentrations of $\mathrm{O}_{2}, \mathrm{~N}_{2}, \mathrm{O}$ and $\mathrm{OH}$ can also play an important role.

The low predicted thermal-NO contribution to the total NO production, the peaks and abundance of measured NO in the fuel-rich regions and the range of temperatures in favor of prompt-NO, all together offer a strong support to the conclusion that prompt-NO mechanism is playing an important role in total $\mathrm{NO}$ production.

The amount of NO formed by prompt-NO is, in general, small. However, the fast kinetic reactions involved in prompt-NO mechanism, make it possible for prompt-NO to contribute significantly to the total NO production, particularly at lower temperatures and higher Reynolds numbers. In fact, a similar result was found earlier when its name was coined; when Fenimore (1970) discovered that some NO was rapidly produced in the flame zone of laminar premixed flames long before there would be time to form NO by thermal-NO mechanism, and he gave this rapidly formed NO the appellation prompt-NO. In conclusions, both thermal-NO and prompt-NO mechanisms should have played an important coupled role in NO production in our diffusion flame and the consequent cascading effect on it.

\subsection{Radial and Axial Velocity Profiles}

Figure 6a shows the radial profiles of the axial velocity component (U) for the baseline and cascaded flames at $\mathrm{x} / \mathrm{d}=80$. This location corresponds to the plane at the mid-level inside venturis number 2 (see Fig. 1). These profiles reveal that the cascaded flame has higher velocities and wider profiles than the baseline flame. The effect of the cascade is small in both the near-burner and fuel-rich regions of the flame. However, the highest effect is observed in the downstream and fuel-lean regions, i.e., the cascade becomes more influential away from the burner-rim in both radial and axial directions.

In general, for a circular jet, the centerline velocity decreases and the jet becomes wider as the jet grows downstream due to the viscous shear and more air entrained. The higher velocities and wider profiles, observed for the cascaded flame compared to the baseline flame, are indications of the rapid and faster growth of the gas jet flame in the 
presence of the cascade. This is due to the effect of the cascade which inducts more of the co-flow air stream into the combustion zone, thereby leading to higher rates of mixing between the fuel and air and the consequent rapid growth of the jet.

The higher effect of the cascade in the fuel-lean side regions, away from the centerline, can be explained by the fact that those regions are closer to the venturis and consequently are expected to be the most affected. Also, the larger effect of the cascade in the downstream regions, and particularly in the far-burner axial location, can be attributed to the cumulative influence of more venturis while proceeding downstream. The higher central axial velocity component in the far-burner region of the cascaded flame and the consequent smaller residence time, compared to the baseline case, can account for the increase in flame length that has been visually observed with the venturicascade.

Figure $6 \mathrm{~b}$ presents the transverse profile of the radial velocity component $(\mathrm{V})$ at the same conditions of Fig. 6a; at the mid-level inside venturis 2. The general trend of these profiles is that the radial velocity is zero at the center line, then it increases to attain a peak value in the fuel-rich region, beyond which it starts decreasing until it reaches a minimum (negative) value close to the stoichiometric contour, then it starts increasing again in the fuel-lean side of the flame to attain an asymptotic value near the flame edge. The positive velocities observed close to centerline imply an outward velocity direction due to jet momentum. On the other hand, the negative velocities noticed farther from the centerline indicate an inward velocity direction. These positive and negative velocities are necessary to satisfy the conservation of mass. A dramatic increase in the inward radial velocities compared to the outward velocities are observed due the effect of the veturicascade. The negative radial velocities with the cascade indicate clearly the generation of an inward flow (towards the centerline of the jet) by the venturis, thereby leading to the higher rates of mixing and its consequent impact on the combustion process. 

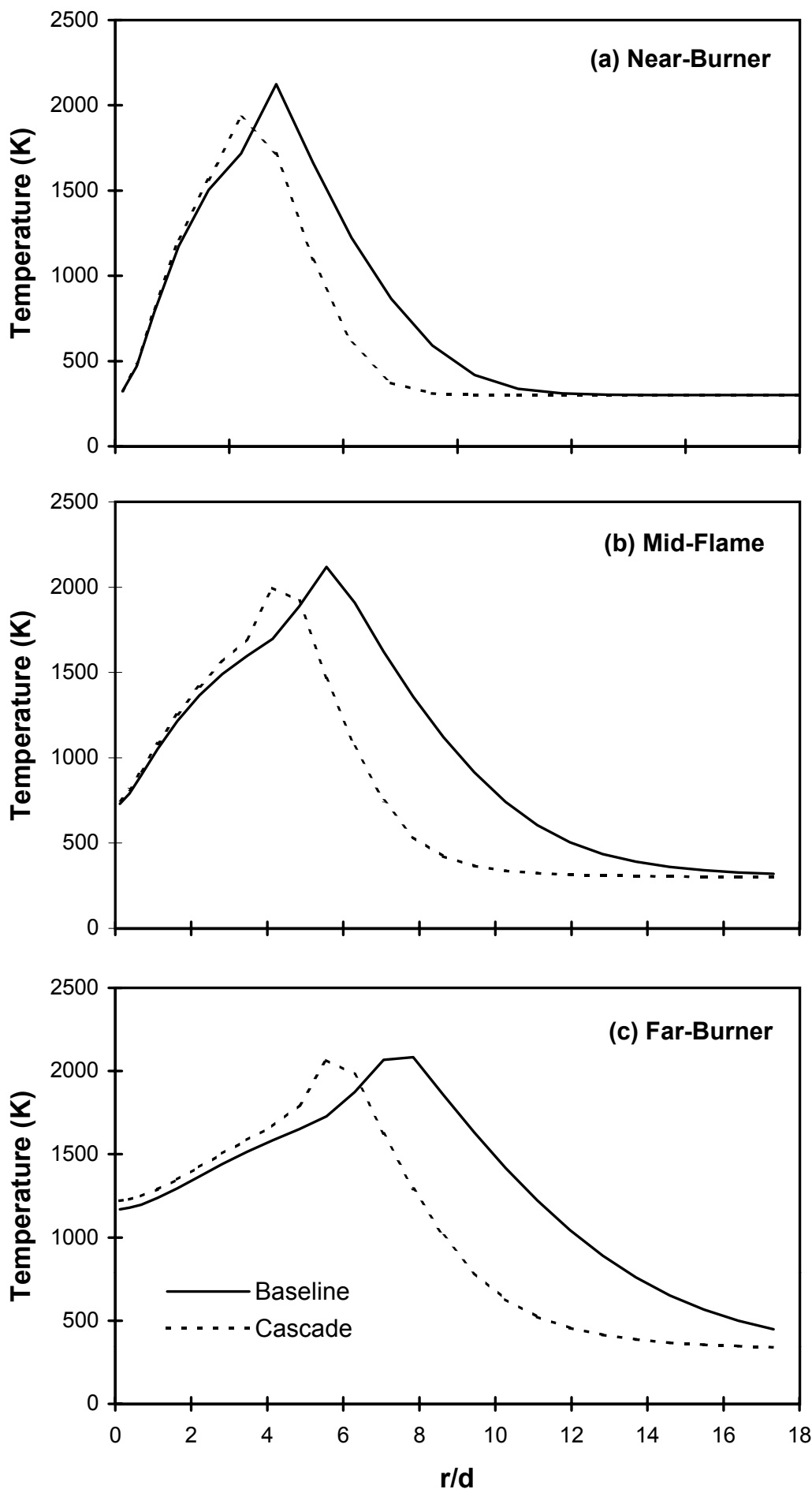

Fig. 2 Radial temperature profiles for the baseline and cascaded flames at different axial locations. 

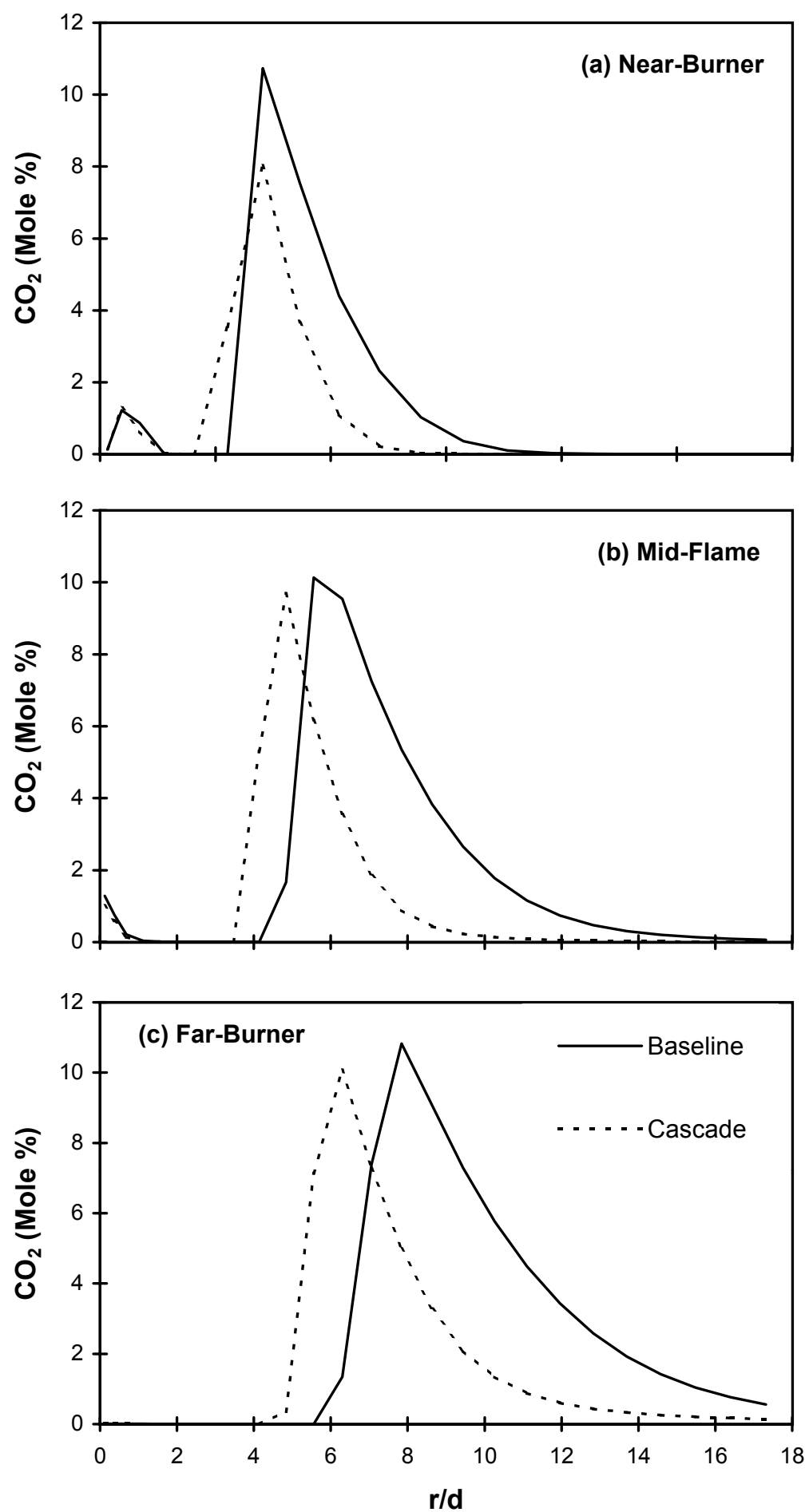

Fig. 3 Radial CO2 profiles for the baseline and cascaded flames at different axial locations. 

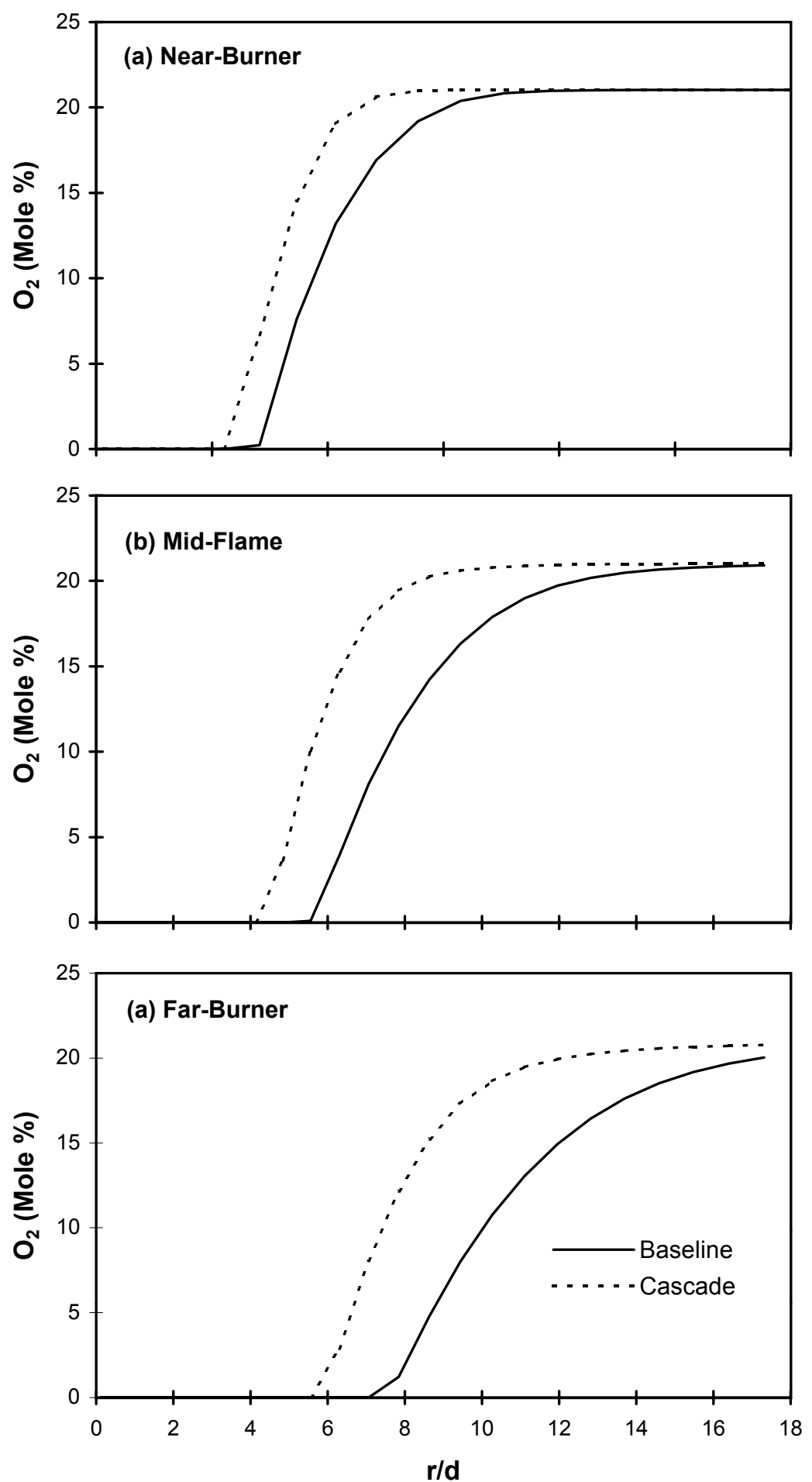

Fig. 4 Radial $\mathrm{O} 2$ profiles for the baseline and cascaded flames at different axial locations 

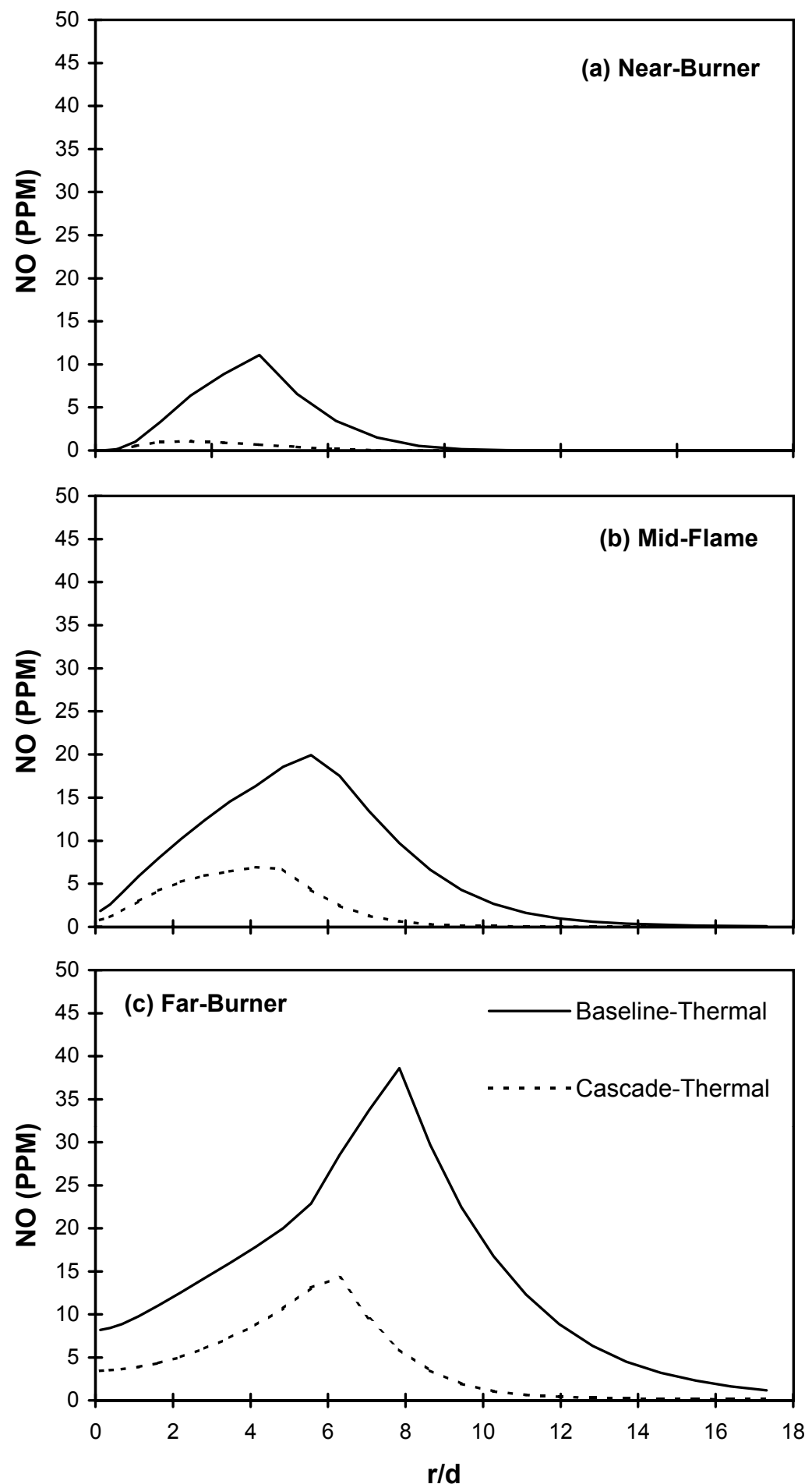

Fig. 5 Radial thermal-NO profiles for the baseline and cascaded flames at different axial locations. 

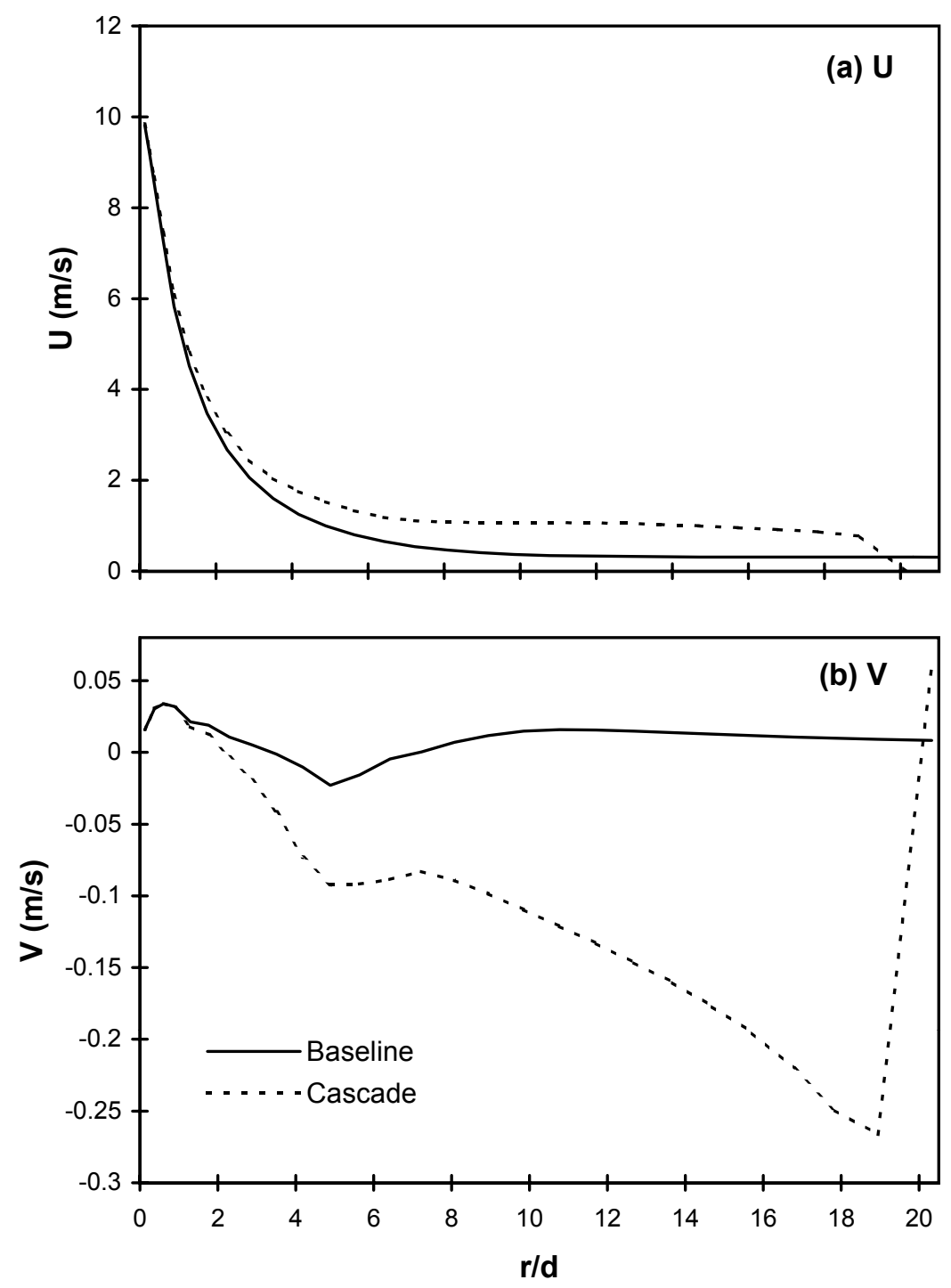

Fig. 6 Radial profiles of axial (U) and radial (V) velocity components for the 


\section{CONCLUSIONS}

The following overall conclusions can be drawn from the present faculty/student exploratory study:

- The numerical results substantiate that venturi-cascading is a feasible method for controlling the pollutant emissions of a burning gas jet.

- The venturi-cascade ejects the co-flow air stream into the core of the combustion zone, thereby leading to better mixing rates of air with the unburned fuel and the consequent impact on the combustion and emission characteristics

- The least influence of the cascade is observed in both the near-burner and fuel-rich regions of the flame. However, the highest effect is in the downstream and fuel-lean regions.

- The prompt-NO mechanism plays a significant role besides thermal-NO mechanism in the current flame configuration.

- The generation of an inward flow (towards the centerline of the jet) and the consequent additional influx of air into the flame, drawn from the computed velocity profiles, can explain the effect of venturi-cascading on the thermo-chemical structure of the flame.

- The computational results of the present study need to be validated experimentally 


\section{REFERENCES}

Bowman, Craig. T. (1992). Control of Combustion-Generated Nitrogen Oxide Emissions: Technology Driven By Regulations. Twenty-Fourth Symposium (International) on Combustion, The Combustion Institute, Pittsburgh, pp 859-878.

CFD Research Corporation (1998). CFD-ACE ${ }^{+}$Theory Manual, Version 5.

Fenimore, C. P. (1970). Formation of Nitric Oxide in Premixed Hydrocarbon Flames. Thirteenth Symposium (International) on Combustion, Combustion Institute, Pittsburgh, PA, pp. 373-380.

Gollahalli, S. R. (1994). Research on Combustion Processes Relevant to Burners in HVAC Systems. Final Report, GRI-94/0420, Gas Research Institute, Illinois, Chicago.

Gollahalli, S. R., Khanna, T., and Prabhu, N. (1992). Diffusion Flames of Gas Jets Issued From Circular and Elliptic Nozzles. Combustion Science and Technology, Vol. 86, pp. 267-288.

Gutmark, E., Shadow, K. C. and Wilson, K. J. (1991). Subsonic and Supersonic Combustion Using Noncircular Injectors. Journal of Propulsion, Vol. 7, No. 2,pp 240-249.

Kamal, A. and Gollahalli, S. R. (1993). Effects of Noncircular Fuel Nozzle on the Pollutant Emission Characteristics of Natural Gas Burner for Residential Furnaces. Combustion, Modeling, Cofiring and NOx control, ASME. FACT. Vol.17 pp. 41-50.

Miller, J. A. and Bowman, C. T. (1989). Mechanisms and Modeling of Nitrogen Chemistry in Combustion. Progress in Energy and Combustion, Vol. 15, p. 287.

Papanikolau, N., Wierzba, I., and Fergusson, B. (1997). The Structure of Jet Diffusion Flames Issuing into Co-Flowing Air Stream. Energy Week, Pennwell publications, Houston, TX, Book V, pp. 222-228.

Papanikolau, N. and Wierzba, I. (1996). Effect of Burner Geometry on the Blowout Limits of Jet Diffusion Flames in a Co-Flowing Air Stream. Journal of Energy Resources Technology, Vol. 118, pp. 134-139.

Shadow, K. C., Gutmark, E., Koshigoe, S., and Wilson, K. J. (1989). Combustion Related Shear-Flow Dynamics in Elliptic Supersonic Jets. AIAA Journal, Vol. 27, No. 10,pp 1347-1353.

Turns, S. R. (1996). An Introduction to Combustion: Concepts and Applications. McGrawHill Inc., NY.

Turns, S. R., Myhr, F. H., Bandaru, R. V. and Mound, E. R. (1993). Oxides of Nitrogen Emissions from Turbulent Jet flames: Part II- Fuel Dilution and Partial Premixing Effects. Combustion and Flame, Vol. 93, pp. 255-269.

Van doormaal, J. P. and Dryer, F. L. (1984). Enhancements of the SIMPLE Methods for Predicting Incompressible Fluid Flows. Numerical Heat Transfer, Vol. 7, pp. 147-163. 


\section{LIST OF ACRONYMS AND ABBREVIATIONS}

A Pre-exponential factor

d Burner-exit diameter

D Venturi throat diameter

DI Venturi inlet diameter

E Activation energy

F Mixture fraction

FDE Finite difference equation

Fr Froude number

$\mathrm{H} \quad$ Venturi height

$\mathrm{k} \quad$ Reaction rate constant

r $\quad$ Radial distance from burner axis

Re Reynolds number

T Temperature

U Axial velocity component

V Radial velocity component

$\mathrm{x} \quad$ Vertical distance above burner exit

Y Mass fraction

I. Greek Symbols

$v \quad$ Stoichiometric coefficient in the overall reaction

$\xi_{\text {ik }} \quad$ Mass fraction of the $i^{\text {th }}$ species in the $\mathrm{k}^{\text {th }}$ mixture

$\underline{\text { Subscripts }}$

f Fuel

i $\quad$ Species $\mathrm{i}$

ox Oxidizer

u Unreacted 